CARPATHIAN J. MATH.

Volume 37 (2021), No. 2,

Pages $203-210$
Online version at https : //www. carpathian. cunbm. utcluj. ro/

Print Edition: ISSN 1584 - 2851; Online Edition: ISSN 1843 - 4401

DOI: https://doi.org/10.37193/CJM.2021.02.06

Dedicated to Prof. Ioan A. Rus on the occasion of his $85^{\text {th }}$ anniversary

\title{
Frum-Ketkov type multivalued operators
}

\author{
ERdal KARAPINAR ${ }^{1,2,3}$, AdRIAN PETRUŞEL ${ }^{4,5}$ and GABRIElA PETRUŞEL ${ }^{6}$
}

ABSTRACT. Let $(M, d)$ be a metric space, $X \subset M$ be a nonempty closed subset and $K \subset M$ be a nonempty compact subset. By definition, an upper semi-continuous multivalued operator $F: X \rightarrow P(X)$ is said to be a strong Frum-Ketkov type operator if there exists $\alpha \in] 0,1\left[\right.$ such that $e_{d}(F(x), K) \leq \alpha D_{d}(x, K)$, for every $x \in X$, where $e_{d}$ is the excess functional generated by $d$ and $D_{d}$ is the distance from a point to a set. In this paper, we will study the fixed points of strong Frum-Ketkov type multivalued operators.

\section{INTRODUCTION}

Let $(\mathbb{B},\|\cdot\|)$ be a Banach space, $K$ be a nonempty compact subset of $\mathbb{B}$ and $f$ : $\tilde{B}(0 ; 1) \rightarrow \tilde{B}(0 ; 1)$ be a continuous operator, where $\tilde{B}(0 ; 1)$ is the closed unit ball in $\mathbb{B}$. We denote by $D_{\|\cdot\|}(x, K)$ the distance from a point $x \in \mathbb{B}$ to the set $K$ from $\mathbb{B}$, i.e., $D_{\|\cdot\|}(x, K):=\inf _{u \in K}\|x-u\|$. In the paper [6], the Russian mathematician Frum-Ketkov proved the existence of a fixed point for the mapping $f$ satisfying the following assumption: there exists $\alpha \in[0,1[$ such that

$$
D_{\|\cdot\|}(f(x), K) \leq \alpha D_{\|\cdot\|}(x, K) \text {, for every } x \in \tilde{B}(0 ; 1) .
$$

For nice extensions of Frum-Ketkov result see [3], [12], [26].

In a recent paper (see [17]), the following more general class of operators is considered and studied. Let $(M, d)$ be a metric space, $X \subset M$ be a nonempty closed subset and $K \subset M$ be a nonempty compact subset. We denote by $D_{d}(x, K)$ the distance from a point $x \in X$ to the set $K$ from $M$, i.e., $D_{d}(x, K):=\inf _{u \in K} d(x, u)$. A continuous operator $f: X \rightarrow X$ is said to be a Frum-Ketkov $(\alpha, K)$-operator if $\alpha \in] 0,1[$ and

$$
D_{d}(f(x), K) \leq \alpha D_{d}(x, K), \text { for every } x \in X .
$$

In the above context, $f: X \rightarrow X$ is called a weakly Picard operator if, for all $x \in X$, the sequence $\left\{f^{n}(x)\right\}_{n \in \mathbb{N}}$ of successive approximations for $f$ converges and its limit $x^{*}(x)$ is a fixed point of $f$. A weakly Picard operator with a unique fixed point is called a Picard operator. See [2] an [24] for details and related results.

In the recent paper [17] sufficient conditions ensuring that a singlevalued Frum-Ketkov operator is weakly Picard were given. The purpose of this paper is to extend the concept of Frum-Ketkov operator to the multivalued setting and to study the properties of the fixed point inclusion with a Frum-Ketkov type multivalued operator.

Received: 16.11.2020. In revised form: 03.05.2021. Accepted: 15.05.2021

2010 Mathematics Subject Classification. 47H10, 54H25, 47H09.

Key words and phrases. metric space, multivalued weakly Picard operator, asymptotic regular multivalued operator, contractive multivalued operator, quasinonexpansive multivalued operator, fixed point, strict fixed point, fixed point structure, Frum-Ketkov operator, strong Frum-Ketkov multivalued operator, Frum-Ketkov selection, asymptotic regularity, asymptotic regular selection.

Corresponding author: Gabriela Petruşel; gabip@math.ubbcluj.ro 


\section{PRELIMINARIES}

Throughout this paper we will use the notations and symbols from [23] and [24]. For the convenience of the reader we recall some of them. Let $(M, d)$ be a metric space. Then, we denote by $P(M)$ the family of all nonempty subsets of $M$, by $P_{c l}(M)$ the family of all nonempty closed subsets of $M$ and by $P_{c p}(M)$ the family of all nonempty compact subsets of $M$. For $x_{0} \in M$ and $R>0$, the symbol $B\left(x_{0} ; R\right)$ denotes the open ball centered at $x_{0}$ with radius $R$, while $\tilde{B}\left(x_{0} ; R\right)$ is the closed ball centered at $x_{0}$ with radius $R$. For $A, B \in P(M)$, we denote by $D_{d}(A, B):=\inf \{d(a, b): a \in A, b \in B\}$ the gap functional generated by $d$ and by $V(Y ; \epsilon)=\left\{x \in M: D_{d}(x, Y) \leq \epsilon\right\}$ the closed neighborhood of the set $Y \subset M$. Recall also that a set $A \in P(M)$ is called proximinal if $(\operatorname{Pr})_{A}(x):=$ $\left\{a \in A: d(x, a)=D_{d}(x, A)\right\} \neq \emptyset$, for each $x \in M$. If $(\mathbb{B},\|\cdot\|)$ is a Banach space, then the symbol $P_{c v}(\mathbb{B})$ denotes the family of all nonempty convex subsets of $\mathbb{B}$, while $P_{c p, c v}(\mathbb{B}):=P_{c p}(\mathbb{B}) \cap P_{c v}(\mathbb{B})$ and $P_{c l, c v}(\mathbb{B}):=P_{c l}(\mathbb{B}) \cap P_{c v}(\mathbb{B})$.

Let $(M, d)$ be a metric space and $F: M \rightarrow P(M)$ be a multivalued operator. Throughout this paper, the symbol Fix $(F):=\{x \in M \mid x \in F(x)\}$ denotes the fixed point set of $F$, while $\operatorname{SFix}(F):=\{x \in X \mid\{x\}=F(x)\}$ is the strict fixed point set of $F$. Also $I(F):=\{Y \subset M: F(Y) \subset Y\}$. For $A, B \in P(M)$, we denote by $H_{d}$ the PompeiuHausdorff functional generated by $d$, i.e.,

$$
H_{d}(A, B):=\max \left\{e_{d}(A, B), e_{d}(B, A)\right\},
$$

where $e_{d}(A, B)$ is the excess of the set $A$ over $B$ and it is represented by the formula

$$
e_{d}(A, B):=\sup \left\{D_{d}(a, B) \mid a \in A\right\} .
$$

We will avoid the subscript $d$ when no confusion can occur. The multivalued operator $F: M \rightarrow P(M)$ is said to be upper semi-continuous on $M$ (briefly u.s.c.) if for each open subset $U$ of $M$, the set $F^{+}(U):=\{x \in M: F(x) \subset U\}$ is open in $M$. On the other hand, the multivalued operator $F$ is said to be lower semi-continuous (briefly 1.s.c.) on $M$ if for each open subset $U$ of $M$ the set $F^{-}(U):=\{x \in M: F(x) \cap U \neq \emptyset\}$ is open in $X$. In the same context, $F$ is called $H$-upper semi-continuous (briefly $H$-u.s.c.) in $x_{0} \in M$ if for all $\epsilon>0$ there exists $\eta>0$ such that, for all $x \in B\left(x_{0} ; \eta\right)$ we have $F(x) \subset V\left(F\left(x_{0}\right) ; \epsilon\right)$. The multivalued operator $F$ is $H$-u.s.c. on $M$ if it is $H$-u.s.c. in each point $x_{0} \in M$. For a multivalued operator with compact values u.s.c. and $H$-u.s.c. are equivalent.

We also recall ([11]) that a multivalued operator $F: M \rightarrow P_{c l}(M)$ is said to be an $\alpha$-contraction if $\alpha \in] 0,1[$ and

$$
H_{d}(F(x), F(y)) \leq \alpha d(x, y) \text {, for all } x, y \in M .
$$

In the same framework, the sequence $\left\{x_{n}\right\}_{n \in \mathbb{N}}$ from $M$ is called a sequence of successive approximations for $F$ starting from $x_{0} \in M$ if $x_{n+1} \in F\left(x_{n}\right)$, for each $n \in \mathbb{N}$.

A multivalued operator $F: M \rightarrow P_{c l}(M)$ is said to be asymptotically regular at the point $x_{0} \in M$ if for any sequence $\left\{x_{n}\right\}_{n \in \mathbb{N}}$ of successive approximations starting from $x_{0}$ we have that $d\left(x_{n}, x_{n+1}\right) \rightarrow 0$ as $n \rightarrow \infty$. If $F$ is asymptotically regular at any point $x_{0} \in M$, then $F$ is said to be asymptotically regular, see [7], [9], [5]. The multivalued operator $F$ is said to be quasi nonexpansive if

$$
H(F(x), F(u)) \leq d(x, u) \text {, for any } x \in M \text { and any } u \in F i x(F) .
$$

Finally, $F$ is called contractive if

$$
H(F(x), F(y))<d(x, y) \text {, for any } x, y \in M \text { with } x \neq y \text {. }
$$

For related concepts see also [8], [27].

Concerning the concept of fixed point structure, we recall the following notion and examples. For other details and results see [22] and [19]. 
Definition 2.1. A triple $\left(X, S(X), M^{0}\right)$ is a fixed point structure on $X$ (f.p.s.) if:

(i) $S(X) \subset P(X), S(X) \neq \emptyset$;

(ii) $M^{0}: P(X) \multimap \bigcup_{Y \in P(X)} \mathbb{M}^{0}(Y), Y \multimap M^{0}(Y) \subset \mathbb{M}^{0}(Y)$ is an operator such that if $Z \in P(Y)$ then $M^{0}(Z) \supset\left\{\left.F\right|_{Z}: F \in M^{0}(Y)\right.$ and $\left.Z \in I(F)\right\}$;

(iii) every $Y \in S(X)$ has the fixed point property with respect to $M^{0}(Y)$, i.e., $Y \in S(X)$, $F \in M^{0}(Y)$ imply $F i x(F) \neq \emptyset$.

Example 2.1. (The f.p.s. of contractive operators) Let $(X, d)$ be a complete metric space, $S(X):=P_{c p}(X)$ and $M^{0}(Y):=\left\{F: Y \rightarrow P_{c l}(Y) \mid F\right.$ is contractive $\}$.

Example 2.2. (The f.p.s. of Bohnenblust-Karlin) Let $X$ be a Banach space, $S(X):=P_{c p, c v}(X)$ and $M^{0}(Y):=\left\{F: Y \rightarrow P_{c p, c v}(Y) \mid F\right.$ is u.s.c. $\}$.

Example 2.3. (The fixed point structure of T. X. Wang) Let $(X, d)$ be a complete metric space, $S(X):=P_{c l}(X), M^{0}(Y):=\left\{F: Y \rightarrow P_{c l}(Y) \mid F\right.$ is such that there exist $a, b \in \mathbb{R}_{+}$ with $a+2 b<1$ and $\left.e_{d}(F(x), F(y)) \leq a d(x, y)+b\left(D_{d}(x, F(x))+c D_{d}(y, F(y))\right), \forall x, y \in Y\right\}$.

\section{FRUM-KETKOV TYPE MULTIVALUED OPERATORS IN METRIC SPACES}

We will present first two concepts of Frum-Ketkov multivalued operators.

Definition 3.2. Let $(M, d)$ be a metric space, $X \in P_{c l}(M)$ and $K \in P_{c p}(M)$. Then, an upper semicontinuous operator $F: X \rightarrow P(X)$ is said to be:

(1) a Frum-Ketkov multivalued $(\alpha, K)$-operator if $\alpha \in] 0,1[$ and

$$
D_{d}(F(x), K) \leq \alpha D_{d}(x, K) \text {, for every } x \in X .
$$

(2) a strong Frum-Ketkov multivalued $(\alpha, K)$-operator if $\alpha \in] 0,1[$ and

$$
e_{d}(F(x), K) \leq \alpha D_{d}(x, K), \text { for every } x \in X .
$$

It is obvious that any strong Frum-Ketkov multivalued $(\alpha, K)$-operator is a FrumKetkov multivalued $(\alpha, K)$-operator, but the reverse implication, in general, does not hold.

We will present first some examples of Frum-Ketkov type multivalued operators.

Remark 3.1. (1) Let $(M, d)$ be a metric space, $X \in P_{c l}(M)$ and $K \in P_{c p}(M)$. If $X \subset K$ then each u.s.c. multi-operator $F: X \rightarrow P(X)$ is a Frum-Ketkov multivalued $(\alpha, K)$ operator, with any $\alpha \in] 0,1[$. In this case, the fixed point theory for Frum-Ketkov multivalued operators reduces to fixed point theory of u.s.c. multivalued operators on compact metric spaces. Thus, as in the single-valued case, the Frum-Ketkov condition is effective if $X \neq K$.

(2) Let $(M, d)$ be a complete metric space, $X \in P_{c l}(M)$ and $F: X \rightarrow P_{c l}(X)$ be a multivalued $\alpha$-contraction. Then, by Nadler's Contraction Principle (see [11], [4]) we know that $\operatorname{Fix}(F) \neq \emptyset$. Let $x^{*}$ be any fixed point of $F$ and $K:=\left\{x^{*}\right\}$. Then $F$ is a Frum-Ketkov multivalued $(\alpha, K)$-operator.

(3) Let $(M, d)$ be a complete metric space, $X \in P_{c l}(M)$ and $F: X \rightarrow P_{c p}(X)$ be a multivalued $\alpha$-contraction. Then, by Nadler's Contraction Principle and Saint Raymond Theorem [25] we have that $F i x(F) \in P_{c p}(X)$. Consider $K:=F i x(F)$. Thus, for each $x \in X$ and any $u \in K$ we can write

$$
D_{d}(F(x), K) \leq D_{d}(u, F(x)) \leq H_{d}(F(u), F(x)) \leq \alpha d(u, x) .
$$

Taking $\inf _{u \in K}$ we obtain

$$
D_{d}(F(x), K) \leq \alpha D_{d}(x, K), \text { for each } x \in X,
$$


proving that $F$ is a Frum-Ketkov multivalued $(\alpha, K)$-operator.

Using the selection theory for multivalued operators we have the following results.

Lemma 3.1. Let $(\mathbb{B},\|\cdot\|)$ be a Banach space, $X \in P_{c l}(\mathbb{B}), K \in P_{c p}(\mathbb{B})$ and $F: X \rightarrow P_{c l, c v}(X)$ be a l.s.c. strong Frum-Ketkov multivalued $(\alpha, K)$-operator. Then there exists a Frum-Ketkov $(\alpha, K)$-selection of $F$.

Proof. Indeed, by Michael' selection theorem (see [10]) there exists a continuous selection $f: X \rightarrow X$ of $F$, i.e., $f(x) \in F(x)$, for each $x \in X$. We have

$$
D_{\|\cdot\|}(f(x), K) \leq e_{\|\cdot\|}(F(x), K) \leq \alpha D_{\|\cdot\|}(x, K), \text { for all } x \in X .
$$

Thus $f$ is a Frum-Ketkov $(\alpha, K)$-operator. As a conclusion, any lower semi-continuous strong Frum-Ketkov multivalued $(\alpha, K)$-operator admits a Frum-Ketkov $(\alpha, K)$-selection.

Lemma 3.2. Let $(\mathbb{B},\|\cdot\|)$ be a Banach space, $X \in P_{c l}(\mathbb{B}), K \in P_{c p}(\mathbb{B})$ and $F: X \rightarrow P_{c l, c v}(X)$ be a l.s.c. strong Frum-Ketkov multivalued $(\alpha, K)$-operator. Additionally, we suppose that there exists a continuous operator $\rho: \mathbb{B} \rightarrow K$ such that $D_{\|\cdot\|}(x, K)=\|x-\rho(x)\|$, for every $x \in X$. Then, there exists a continuous selection $f$ of $F$ which is $\rho$-asymptotically regular.

Proof. By Michael' selection theorem there exists a continuous selection $f: X \rightarrow X$ of $F$. By the additional hypothesis we know that there exists a continuous operator $\rho: \mathbb{B} \rightarrow K$ such that $D_{\|\cdot\|}(x, K)=\|x-\rho(x)\|$, for every $x \in X$. Combining the above relation with the fact that $f(x) \in F(x)$, for each $x \in X$, we have

$$
\|f(x)-\rho(f(x))\|=D_{\|\cdot\|}(f(x), K) \leq e_{\|\cdot\|}(F(x), K) \leq \alpha D_{\|\cdot\|}(x, K)=\alpha\|x-\rho(x)\| .
$$

This implies that

$$
\left\|f^{n}(x)-\rho\left(f^{n}(x)\right)\right\| \leq \alpha^{n}\|x-\rho(x)\| \rightarrow 0, \text { as } n \rightarrow \infty, \text { for each } x \in X .
$$

As a consequence, the continuous selection $f$ of $F$ is $\rho$-asymptotically regular.

Concerning the properties of a Frum-Ketkov multivalued $(\alpha, K)$-operator we have the following result.

Theorem 3.1. Let $(M, d)$ be a metric space, $X \in P_{c l}(M)$ and $K \in P_{c p}(M)$. Suppose that $F: X \rightarrow P_{c p}(X)$ is a Frum-Ketkov multivalued $(\alpha, K)$-operator. Then, for every $x_{0} \in X$ there exists a sequence $\left(x_{n}\right)_{n \in \mathbb{N}}$ of successive approximations for $F$ starting from $x_{0}$ which has a convergent subsequence.

Proof. Let $x_{0} \in X$ be arbitrary chosen. Since $F$ has compact values, there exists $x_{1} \in F\left(x_{0}\right)$ such that $D_{d}\left(F\left(x_{0}\right), K\right)=D_{d}\left(x_{1}, K\right)$. By this approach, we can obtain a sequence $\left\{x_{n}\right\}_{n \in \mathbb{N}}$ of successive approximations for $F$ starting from $x_{0}$ having the property

$$
D_{d}\left(F\left(x_{n}\right), K\right)=D_{d}\left(x_{n+1}, K\right), \text { for } n \in \mathbb{N} .
$$

Moreover, we have

$$
D_{d}\left(x_{n+1}, K\right)=D_{d}\left(F\left(x_{n}\right), K\right) \leq \alpha D_{d}\left(x_{n}, K\right) \leq \cdots \leq \alpha^{n+1} D\left(x_{0}, K\right) \rightarrow 0 \text {, as } n \rightarrow \infty .
$$

Using the compactness of $K$ there exists a sequence $\left\{y_{n}\right\}_{n \in \mathbb{N}}$ in $K$ such that

$$
D_{d}\left(x_{n}, K\right)=d\left(x_{n}, y_{n}\right) \text {, for } n \in \mathbb{N} \text {. }
$$

Using again the compactness of $K$, we can find a subsequence $\left\{y_{n_{i}}\right\}$ of $\left\{y_{n}\right\}$ which converges to an element $u^{*} \in K$ as $n_{i} \rightarrow \infty$. As a consequence, $\left\{x_{n_{i}}\right\}$ also converges to $u^{*} \in X \cap K$ as $n_{i} \rightarrow \infty$. 
Remark 3.2. It is an open question to obtain that $u^{*}$ from the above proof is a fixed point for $F$.

We will consider now the case of a strong Frum-Ketkov multivalued $(\alpha, K)$-operator.

Theorem 3.2. Let $(M, d)$ be a metric space, $X \in P_{c l}(M)$ and $K \in P_{c p}(M)$. Suppose that $F: X \rightarrow P_{c l}(X)$ is a strong Frum-Ketkov multivalued $(\alpha, K)$-operator. Then, the following conclusions hold:

(a) every sequence $\left\{x_{n}\right\}_{n \in \mathbb{N}}$ of successive approximations for $F$ starting from arbitrary $x_{0} \in X$ has a convergent subsequence;

(b) Fix $(F) \subset X \cap K$;

(c) $X \cap K$ is invariant with respect to $F$, i.e., $F(X \cap K) \subset X \cap K$;

(d) if, additionally, $F$ is asymptotically regular, then $F i x(F) \neq \emptyset$; Moreover, if $F$ has proximinal values and it is quasi nonexpansive, then for any $x_{0} \in X$ there exists a sequence of successive approximations for $F$ starting from $x_{0}$ which converges to a fixed point of $F$.

Proof. (a) Let $x_{0} \in X$ be arbitrary chosen. Then, for $x_{1} \in F\left(x_{0}\right)$ we have

$$
D_{d}\left(x_{1}, K\right) \leq e_{d}\left(F\left(x_{0}\right), K\right) \leq \alpha D_{d}\left(x_{0}, K\right) .
$$

Thus, for every sequence $\left\{x_{n}\right\}$ of successive approximations for $F$ starting from arbitrary $x_{0}$ we obtain, for every $n \in \mathbb{N}$, that

$$
D_{d}\left(x_{n}, K\right) \leq e_{d}\left(F\left(x_{n-1}\right), K\right) \leq \alpha D\left(x_{n-1}, K\right) \leq \cdots \leq \alpha^{n} D_{d}\left(x_{0}, K\right) \rightarrow 0 \text {, as } n \rightarrow \infty .
$$

Since $K$ is compact, there exists a sequence $\left\{y_{n}\right\}_{n \in \mathbb{N}}$ in $K$ such that

$$
D_{d}\left(x_{n}, K\right)=d\left(x_{n}, y_{n}\right) \text {, for } n \in \mathbb{N} \text {. }
$$

Using again the compactness of $K$, we can find a subsequence $\left\{y_{n_{i}}\right\}$ of $\left\{y_{n}\right\}$ which converges to an element $u^{*} \in K$ as $n_{i} \rightarrow \infty$. By the above relations, we get that $\left\{x_{n_{i}}\right\}$ also converges to $u^{*} \in X \cap K$ as $n_{i} \rightarrow \infty$.

(b) Let $u \in F i x(F)$. Then

$$
D_{d}(u, K) \leq e_{d}(F(u), K) \leq \alpha D_{d}(u, K) .
$$

Thus $D_{d}(u, K)=0$, which implies that $u \in K$. Hence $u \in X \cap K$.

(c) Let $x \in X \cap K$. Then $e_{d}(F(x), K) \leq \alpha D_{d}(x, K)=0$. Thus we get that $F(x) \subset \bar{K}=K$. As a conclusion, $F(x) \subset X \cap K$.

(d) By (a) we know that any sequence $\left\{x_{n}\right\}$ of successive approximations for $F$ has a convergent subsequence. Say that $\left\{x_{n_{i}}\right\}$ converges to $u^{*} \in X \cap K$ as $n_{i} \rightarrow \infty$. Since $F$ is asymptotically regular, for any sequence $\left\{x_{n}\right\}$ of successive approximations for $F$ starting from arbitrary $x_{0}$, we have that $d\left(x_{n}, x_{n+1}\right) \rightarrow 0$ as $n \rightarrow \infty$. Then, using the upper semi-continuity assumption on $F$, we get that

$$
D\left(u^{*}, F\left(u^{*}\right)\right) \leq d\left(u^{*}, x_{n_{i}}\right)+d\left(x_{n_{i}}, x_{n_{i}+1}\right)+e_{d}\left(F\left(x_{n_{i}}\right), F\left(u^{*}\right)\right) \rightarrow 0 \text { as } n_{i} \rightarrow \infty .
$$

Thus $u^{*} \in F i x(F)$.

For the second conclusion of this item, since $F$ has proximinal values, for $x_{0} \in X$ there exists $x_{1} \in F\left(x_{0}\right)$ such that $d\left(x_{1}, u^{*}\right)=D\left(F\left(x_{0}\right), u^{*}\right)$. Inductively we obtain a sequence $\left\{x_{n}\right\}$ of successive approximations for $F$ with $d\left(x_{n+1}, u^{*}\right)=D\left(F\left(x_{n}\right), u^{*}\right), n \in \mathbb{N}$. Then, by the quasi nonexpansivity of $F$, we get that

$$
d\left(x_{n+1}, u^{*}\right)=D\left(F\left(x_{n}\right), u^{*}\right) \leq H_{d}\left(F\left(x_{n}\right), F\left(u^{*}\right)\right) \leq d\left(x_{n}, u^{*}\right), n \in \mathbb{N} .
$$

This shows that the sequence $\left\{d\left(x_{n}, u^{*}\right)\right\}$ is decreasing and, hence, convergent. Since the subsequence $\left\{d\left(x_{n_{i}}, u^{*}\right)\right\}$ is convergent to 0 , the whole sequence $\left\{d\left(x_{n}, u^{*}\right)\right\}$ converges also to 0 . Hence, $x_{n} \rightarrow u^{*}$ and thus there exists a sequence of successive approximations which converges to $u^{*} \in F i x(F)$. 
Remark 3.3. It is an open question to obtain strict fixed point theorems for strong FrumKetkov multivalued $(\alpha, K)$-operators. For strict fixed point theorems see [1], [15], [16], [18], [20].

\section{FRUM-KETKOV OPERATORS IN TERMS OF A FIXED POINT STRUCTURE}

Let $F: X \rightarrow P_{c l}(X)$ be a strong Frum-Ketkov multivalued operator. By Theorem 3.2 we have that $X \cap K \neq \emptyset, F(X \cap K) \subset X \cap K$ and $F i x(F) \subset X \cap K$.

Let $\left(M, \mathbb{S}(M), M^{0}\right)$ be a fixed point structure. If $X \cap K \in \mathbb{S}(M)$ and the restriction of $F$ to $X \cap K$ belongs to $M^{0}(X \cap K)$, then $F i x(F) \neq \emptyset$. Thus, we can prove the following result.

Theorem 4.3. Let $(M, d)$ be a complete metric space, $X \in P_{c l}(M)$ and $K \in P_{c p}(M)$. Suppose that $F: X \rightarrow P_{c l}(X)$ is contractive and there exists $\left.\alpha \in\right] 0,1[$ such that

$$
e_{d}(F(x), K) \leq \alpha D_{d}(x, K) \text {, for every } x \in X \text {. }
$$

Then $\operatorname{Fix}(F) \neq \emptyset$.

Proof. We consider on $M$ the fixed point structure $\left(M, P_{c p}(M), M^{0}\right)$, where for $Y \in P_{c p}(M)$ we define

$$
M^{0}(Y):=\left\{G: Y \rightarrow P_{c l}(Y): \mathrm{G} \text { is contractive }\right\} .
$$

Since $X \cap M \in P_{c p}(M)$ and $\left.F\right|_{X \cap K} \in M^{0}(X \cap M)$, the conclusion follows by the definition of the fixed point structure of Smithson, see [22].

A similar result can be obtained by using the fixed point structure of BohnenblustKarlin, see [22].

Theorem 4.4. Let $(\mathbb{B},\|\cdot\|)$ be a Banach space, $X \in P_{c l, c v}(\mathbb{B})$ and $K \in P_{c p, c v}(\mathbb{B})$. Suppose that $F: X \rightarrow P_{c l, c v}(X)$ is a strong Frum-Ketkov multivalued operator. Then Fix $(F) \neq \emptyset$.

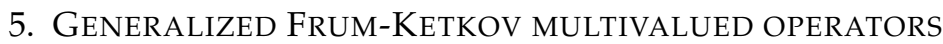

We present first the notion of generalized Frum-Ketkov multivalued operator.

Definition 5.3. Let $(M, d)$ be a metric space, $X \in P_{c l}(M)$ and $K \in P_{c p}(M)$. Then, by definition, $F: X \rightarrow P(X)$ is a generalized Frum-Ketkov multivalued operator if $F$ is u.s.c. and there exists a sequence $\left\{x_{n}\right\}_{n \in \mathbb{N}}$ of successive approximations for $F$ starting from any $x_{0} \in X$ such that $D_{d}\left(x_{n}, K\right) \rightarrow 0$ as $n \rightarrow \infty$.

Example 5.4. Let $(M, d)$ be a metric space, $X \in P_{c l}(M), K \in P_{c p}(M)$. Let $F: X \rightarrow P_{c p}(X)$ be an u.s.c. multivalued operator. If $\varphi: \mathbb{R}_{+} \rightarrow \mathbb{R}_{+}$is a comparison function (i.e., $\varphi$ is increasing and the sequence $\left\{\varphi^{n}(t)\right\}_{n \in \mathbb{N}}$ converges to 0 as $n \rightarrow \infty$, for every $\left.t>0\right)$ and

$$
D_{d}(F(x), K) \leq \varphi\left(D_{d}(x, K)\right) \text {, for every } x \in X,
$$

then $F$ is a generalized Frum-Ketkov multivalued operator. In this case $F$ is called a Frum-Ketkov multivalued $\varphi$-operator.

Example 5.5. Let $(M, d)$ be a metric space, $X \in P_{c l}(M)$ and $K \in P_{c p}(M)$. Let $F: X \rightarrow$ $P(X)$ be an u.s.c. multivalued operator. If $\varphi: \mathbb{R}_{+} \rightarrow \mathbb{R}_{+}$is a comparison function and

$$
e_{d}(F(x), K) \leq \varphi\left(D_{d}(x, K)\right) \text {, for every } x \in X,
$$

then $F$ is a generalized Frum-Ketkov multivalued operator. In this case $F$ is called a strong Frum-Ketkov multivalued $\varphi$-operator. 
Example 5.6. Let $(M, d)$ be a metric space, $X \in P_{c l}(M), K \in P_{c p}(M)$. Let $F: X \rightarrow P_{c p}(X)$ be an u.s.c. operator such that for every $\varepsilon>0$ there exists $\delta>0$ such that

$$
\varepsilon \leq D_{d}(x, K)<\varepsilon+\delta \Rightarrow D_{d}(F(x), K)<\varepsilon .
$$

Then, $F$ is a generalized Frum-Ketkov multivalued operator, i.e., there is a sequence $\left\{x_{n}\right\}$ of successive approximations for $F$ starting from arbitrary $x_{0} \in X$ having the property $D_{d}\left(x_{n}, K\right) \rightarrow 0$ as $n \rightarrow \infty$, for every $x \in X$. Indeed, since $d_{n}:=D_{d}\left(x_{n}, K\right)$ is decreasing, we can suppose, by contradiction, that $d_{n} \searrow \varepsilon>0$ as $n \rightarrow \infty$. Assuming, for some $m \in \mathbb{N}^{*}$, that $d_{m}<\varepsilon+\delta$, we get, by the definition of $F$, that $d_{m+1}<\varepsilon$, which gives the desired contradiction.

The main result for this section is the following theorem.

Theorem 5.5. Let $(M, d)$ be a metric space, $X \in P_{c l}(M)$ and $K \in P_{c p}(M)$. Suppose that $F: X \rightarrow P(X)$ is a generalized Frum-Ketkov operator. Then, the following conclusions hold:

(a) there exists a sequence $\left\{x_{n}\right\}_{n \in \mathbb{N}}$ of successive approximations for $F$ starting from arbitrary $x_{0} \in X$ which has a convergent subsequence;

(b) if, additionally, $F$ is asymptotically regular, then $F i x(F) \neq \emptyset$.

Proof. (a) By the hypothesis, we know that $F$ is u.s.c. and there exists a sequence $\left\{x_{n}\right\}_{n \in \mathbb{N}}$ of successive approximations for $F$ starting from any $x_{0} \in X$ such that $D_{d}\left(x_{n}, K\right) \rightarrow 0$ as $n \rightarrow \infty$. Since $K$ is compact, there exists a sequence $\left\{y_{n}\right\}_{n \in \mathbb{N}}$ in $K$ such that

$$
D_{d}\left(x_{n}, K\right)=d\left(x_{n}, y_{n}\right) \text {, for } n \in \mathbb{N} \text {. }
$$

Using again the compactness of $K$, we can find a subsequence $\left\{y_{n_{i}}\right\}$ of $\left(y_{n}\right)$ which converges to an element $u^{*} \in K$ as $n_{i} \rightarrow \infty$. Thus, the subsequence $\left\{x_{n_{i}}\right\}$ also converges to $u^{*} \in X \cap K$ as $n_{i} \rightarrow \infty$.

(b) By (a) we know that there exists a sequence $\left\{x_{n}\right\}$ of successive approximations for $F$ which has a convergent subsequence. Say that $\left\{x_{n_{i}}\right\}$ converges to $u^{*} \in X \cap K$ as $n_{i} \rightarrow \infty$. By the asymptotically regularity of $F$, the sequence $\left\{x_{n}\right\}$ of successive approximations for $F$ starting from arbitrary $x_{0}$ has the property that $d\left(x_{n}, x_{n+1}\right) \rightarrow 0$ as $n \rightarrow \infty$. Then, using the upper semi-continuity assumption on $F$, we get that

$$
D\left(u^{*}, F\left(u^{*}\right)\right) \leq d\left(u^{*}, x_{n_{i}}\right)+d\left(x_{n_{i}}, x_{n_{i}+1}\right)+e_{d}\left(F\left(x_{n_{i}}\right), F\left(u^{*}\right)\right) \rightarrow 0 \text { as } n_{i} \rightarrow \infty .
$$

Thus $u^{*} \in F i x(F)$.

Example 5.7. Let $M:=\mathbb{R}^{2}, d:=d_{\|\cdot\|_{2}}, X=[0,1] \times[0,1]$ and $K:=[0,1] \times\{0\}$. Let $F: X \rightarrow$ $P(X)$ be a multivalued operator defined by $F\left(x_{1}, x_{2}\right)=\left\{\left(1-x_{1}, \frac{1}{2} x_{2}\right),\left(x_{1}, \frac{1}{2} x_{2}\right)\right\}$. Then, $F$ is a strong Frum-Ketkov multivalued operator with $F i x(F)=\left\{\left(x_{1}, 0\right): x_{1} \in[0,1]\right\}$ and $\operatorname{SFix}(F)=\left\{\left(\frac{1}{2}, 0\right)\right\}$. Moreover, $F$ is not asymptotically regular in $(x, 0)$, for $x \in[0,1] \backslash\left\{\frac{1}{2}\right\}$.

\section{REFERENCES}

[1] Avramescu, C., Théorèmes de point fixe pour les applications contractantes et anticontractantes, Manuscripta Math., 6 (1972), 405-411

[2] Berinde, V., Iterative Approximations of Fixed Points, Springer Berlin, 2007

[3] Buley, H., Fixed point theorems of Rothe-type for Frum-Ketkov and 1-set-contractions, Comment. Math. Univ. Carol., 19 (1978), No. 2, 213-225

[4] Covitz, H. and Nadler, S. B. Jr., Multivalued contraction mappings in generalized metric spaces, Israel J. Math., 8 (1970), 5-11

[5] Debnath, P. and De La Sen, M., Contractive inequalities for some asymptotically regular set-valued mappings and their fixed points, Symmetry, 12 (2020), No. 3, 411

[6] Frum-Ketkov, R. L., Mapping into a sphere of a Banach space (Russian), Dokl. Akad. Nauk SSSR, 175 (1967), 1229-1231 
[7] Garegnani, G. and Zanco, C., Fixed points of somehow contractive multivalued mappings, Istit. Lombardo Accad. Sci. Lett. Rend. A., 114 (1980), 138-148

[8] Huang, Jui-Chi, Common fixed points of asymptotically hemicontractive mappings, Indian J. Pure Appl. Math., 33 (2002), 1811-1825

[9] Massa, S. and Roux, D., On the minimal displacement under generalized nonexpansive multivalued mappings, Rend. Mat., 12 (1979), No. 3-4, 577-585

[10] Michael, E., Continuous selections. I., Annals of Mathematics. Second Series 63 (1956), No. 2, 361-382

[11] Nadler, S. B. Jr., Multivalued contraction mappings, Pacific J. Math., 30 (1969), 475-488

[12] Park, S. and Kim, W. K., On the Frum-Ketkov type fixed point theorems, Bull. Korean Math. Soc., 20 (1983), No. $1,5-8$

[13] Pasicki, L., Multivalues selections, Bull. Polish Acad. Sci. Math., 45 (1997), No. 1, 81-88

[14] Petruşel, A., Multivalued weakly Picard operators and applications, Sci. Math. Jpn., 59 (2004), No. 1, 169-202

[15] Petruşel, A. and Petruşel, G., Some variants of the contraction principle for multi-valued operators, generalizations and applications, J. Nonlinear Convex Anal., 20 (2019), 2187-2203

[16] Petruşel, A., Rus, I. A. and Şerban, M.-A., Basic problems of the metric fixed point theory and the relevance of a metric fixed point theorem for multivalued operators, J. Nonlinear Convex Anal., 15 (2014), 493-513

[17] Petruşel, A., Rus, I. A. and Şerban, M.-A., Frum-Ketkov operators which are weakly Picard, Carpathian J. Math., 36 (2020), 295-302

[18] Rus, I. A., Fixed and strict fixed points for multivalued mappings, Seminar Fixed Point Theory Cluj-Napoca, Babeş-Bolyai University, 1985, 77-82

[19] Rus, I. A., Techniques of the fixed point structures for multivalued operators, Math. Japon., 38 (1993), 289-296

[20] Rus, I. A., Strict fixed point theory, Fixed Point Theory, 4 (2003), 177-183

[21] Rus, I. A., Petruşel, A. and Sîntămărian, A., Data dependence of the fixed point set of some multivalued weakly Picard operators, Nonlinear Anal., 52 (2003), No. 8, 1947-1959

[22] Rus, I. A., Fixed Point Structure Theory, Cluj Univ. Press Cluj-Napoca, 2006

[23] Rus, I. A., Petruşel, A. and Petruşel, G., Fixed Point Theory, Cluj University Press Cluj-Napoca, 2008

[24] Rus, I. A and Şerban, M. A., Basic problems of the metric fixed point theory and the relevance of a metric fixed point theorem, Carpathian J. Math., 29 (2013), No. 2, 239-258

[25] Saint-Raymond, J., Multivalued contractions, Set-Valued Anal., 2 (1994), 559-571

[26] Schöneberg, R., Some fixed point theorems for mappings satisfying Frum-Ketkov conditions, Comment. Math. Univ. Carol., 17 (1976), No. 2, 399-411

[27] Schu, J., Weak and strong convergence to fixed points of asymptotically nonexpansive mappings, Bull. Austral. Math. Soc., 43 (1991), 153-159

[28] Smithson, R. E., Fixed points for contractive multifunctions, Proc. Amer. Math. Soc., 27 (1971), 192-194

[29] Wang, T. X., Fixed-point theorems and fixed-point stability for multivalued mappings on metric spaces, Nanjing Daxue Xuebao Shuxue Bannian Kan, 6 (1989), No. 1, 16-23

${ }^{1}$ Division of Applied Mathematics

Thu Dau Mot University, Binh Duong Province, Vietnam

E-mail address: erdalkarapinaretdmu.edu.vn

2 Department of Mathematics

ÇANKAYA UNIVERSITY, 06790, ETIMESGUT, ANKARA, TURKEY

E-mail address: erdalkarapinar@yahoo.com

${ }^{3}$ Department of Medical Research

China Medical University Hospital

China Medical University, 40402, TAICHUNG, TAIWAN

E-mail address: karapinar@mail. cmuh. org.tw

${ }^{4}$ Department of MATHEMATICS

BABEŞ-BOlyai UNIVERSITY CLUJ-NAPOCA, ROMANIA

${ }^{5}$ ACADEMY OF ROMANIAN SCIENTISTS

BUCHAREST, ROMANIA

E-mail address: petrusel@math.ubbcluj.ro

${ }^{6}$ DePARTMENT OF BUSINESS

BABEŞ-BOlyai UNIVERSITY ClUJ-NAPOCA, ROMANIA

E-mail address: gabip@math.ubbcluj.ro 